\title{
The Current Studies of Education for a Traditional and Complementary Medicine in Malaysia
}

Yun Jin Kim

Department of Chinese Medicine, Southern University College, Malaysia

*Corresponding author: Yun Jin Kim, Department of Chinese Medicine, Southern University College, Malaysia, Tel: 60-127337661; E-mail: neurokim76@naver.com Received date: June 01, 2017; Accepted date: June 14, 2017; Published date: June 21, 2017

Copyright: (c) $2017 \mathrm{Kim}$ YJ. This is an open-access article distributed under the terms of the Creative Commons Attribution License, which permits unrestricted use, distribution, and reproduction in any medium, provided the original author and source are credited.

\begin{abstract}
The aim of this study is to understand the current T\&CM education in Malaysia. We referred to literatures regarding to traditional medicine education in Malaysia, and collected the information via website or interview with Faculty of T\&CM in universities/colleges and Division of T\&CM, Ministry of Health, Malaysia. T\&CM education in Malaysia has been following China's TCM systems for 50 years. Currently, Division of T\&CM, Ministry of Health; and Ministry of Higher Education; has approved 11 institutions to offer T\&CM education. Students may major in Chinese Herbal Medicine, Acupuncture or other T\&CM subjects. Generally, clinical training programs in China, Taiwan or Australia include substantial proportion of clinical training. We reported the general information of T\&CM education in Malaysia. This result would be the first stage information for an establishment of a strategy regarding the enhancement of Malaysia education for T\&CM.
\end{abstract}

Keywords Traditional medicine; Complementary medicine; Medical education

\section{Traditional and Complementary Medicine}

Traditional \& Complementary Medicine (T\&CM) is an ancient medical practice that existed in human societies before the application of modern science to health. It has evolved to reflect different philosophical background and cultural origins. In recent decades, usage of Traditional \& Complementary Medicine has been increasing rapidly throughout the world and its acceptance has increased significantly [1]. The practice of modern medicine may be widespread but the use of Traditional \& Complementary Medicine is still practiced in many countries although it is not always included as a part of the healthcare system recognized by the government. T\&CM has been widely utilized by the world population for decades. In some Asian and African countries, $80 \%$ of the populations depend on T\&CM for primary health care purposes [2]. A report from 'Global Industry Analysts, Inc' presented that the world market size of T\&CM industry will grow from 89.8 billion US dollars in 2011 to 114.1 billion US dollars in 2014, at a growth rate of $6.0 \%$ annually [3].

Since the geographical transfer of Traditional Chinese Medicine from Mainland China, there has been a dependence on imported herbal medications by T\&CM practitioners in other Eastern and Southeast Asian countries (Malaysia, Singapore, and Thailand), whose clientele prefer herbal medicine products from Mainland China. However there has been an interesting in developing local sources of herbal medicine plants and products [4]. All member countries in the Southeast Asian region are assisting WHO in developing, strengthening and introducing the use of Traditional Medicine into primary health care, which was marginalized as a result of sociocultural changes. In Thailand, there has recently been an attempt to revitalize Traditional Thai Medicine for the benefit of the Thailand healthcare system especially in rural areas [5]. T\&CM has made a significant contribution to the health care of the Malaysian community. It continues to be patronized by Malaysian people in their bid to seek treatment for disease and in maintaining health. Siti et al. [6] reported that the prevalence of use of T\&CM amongst Malaysians in their lifetime was $69.4 \%(67.6 \%$ to $71.2 \%)$ and $55.6 \%$ (53.8\% to $57.4 \%)$ within the last period of 12 months of the study.

Enhancing the professionalism of graduates is a major objective of most health care education institutions today. Educating conventional health care providers about T\&CM may directly and indirectly improve trainee professionalism by expanding trainees' knowledge and appreciation of diverse health care benefits and medical practices, improving T\&CM physician-to-patient communication, enhancing self-care, and increasing sense of competence and job satisfaction [7]. Realizing this, the Ministry of Health and Ministry of Higher Education, Malaysia took a positive and proactive approach in nurturing T\&CM to ensure the quality, safety of practices and education of T\&CM.

T\&CM is a system of medicine that incorporates Chinese Herbal Medicine, Acupuncture, Moxibustion, Guasha, Cupping, Tui-na, Natural Medicine, Homeopathy, Malay Medicine, Malay Massage, Ayurveda Medicine, Chiropractic, Reflexology, Aromatherapy and Islamic Medicine. T\&CM was introduced in Malaysia during 1878. Since 2016 Malaysia has regulated the practice of T\&CM on a national level. The registration of T\&CM practitioners has paved the way for integration of T\&CM into the mainstream healthcare system of Malaysia. Furthermore, in response to the increasing interest of healthcare consumers, the Malaysian T\&CM workforce has markedly expanded over the past decades. According to the statistical data obtained from the Division of T\&CM, Ministry of Health, Malaysia, as on 2011, a total of 4910 local T\&CM practitioners had registered with the e-PENGAMAL system since 2008. The largest increment for the registration of local practitioners was noted in 2011 with a total of 2631 T\&CM practitioners.

This was attributed to a series of dialogues held throughout the country. Traditional Chinese Medicine practitioners (66\%) recorded the highest percentage from the total number of practitioners, followed by Complementary Medicine practitioners (13\%) and Traditional 
Page 2 of 6

Malay Medicine practitioners (11\%). The number of Traditional Chinese Medicine practitioners and Islamic Medical practitioners progressively increased in 2011 due to initiatives taken by the respective Practitioner Bodies (Figure 1) [8].

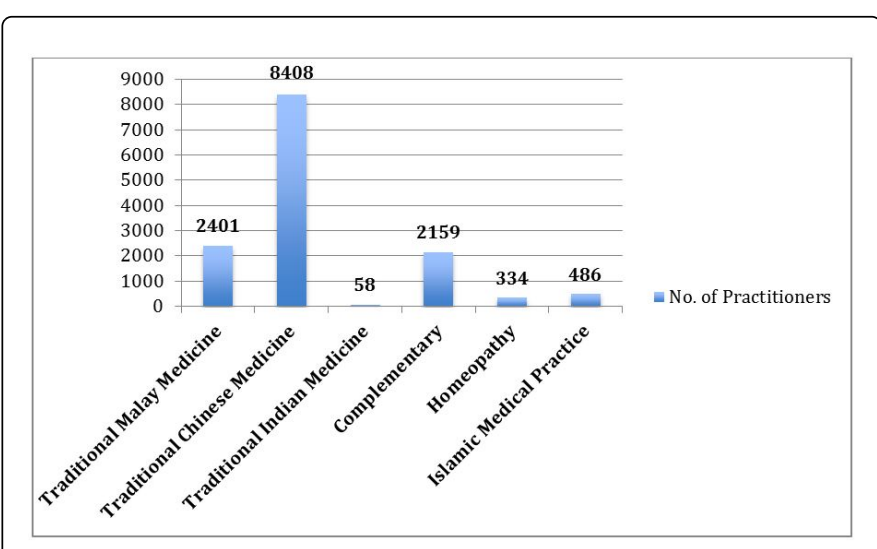

Figure 1: Progressive increase of traditional Chinese medicine practitioners and Islamic Medical practitioners over the years.

This study aimed to review the current situation of T\&CM education in Malaysia.

\section{Materials and Methods}

\section{Study design and Setting}

This study reviewed the literatures related to Traditional Medicine education in Malaysia, obtained relevant information via Traditional Medicine Universities/Colleges websites, interviewed (Based on school visit) with 11 Deans or Heads of Department from Traditional Medicine Universities/Colleges in Malaysia, and Email interviewed with 2 Officers and 1 Director from Division of T\&CM, Ministry of Health, Malaysia. Each university/college's Interview includes current student numbers, type of courses offered, study plan, T\&CM course syllabus, total graduate credits and total clinical practice duration, while Email interview from Division of T\&CM, Ministry of Health, Malaysia collects information that includes number of registered practitioners on E-PENGAMAL system, current status for government hospitals, T\&CM Strategy, National T\&CM policy/guidelines, and T\&CM Acts 2016 (as shown in Appendix).

\section{Data collection and analysis}

Beside interview (Based on school visit) with Dean or Head of Department from Universities/Colleges, Email interview with Division of T\&CM, Ministry of Health, Malaysia, literature review was also done by referring to electronic databases, such as CNKI (http:// www.cnki.net), and Pubmed (http://www.ncbi.nlm.nih.gov/pubmed), with keywords like "Traditional Medicine", "Malaysia", "Malay medicine", "Traditional Complementary Medicine", "Alternative Medicine", and "Education". Related reports and articles were searched from government-related organizations, including Division of T\&CM, Ministry of Health, Malaysia (http://tcm.moh.gov.my), and Malaysia local T\&CM Universities/Colleges websites.

\section{Results}

\section{Brief introduction history of T\&CM in Malaysia}

The ancient Malaysia received its first medical knowledge from Portugal, the Netherlands, and United Kingdom in the $15^{\text {th }}$ century, before the $15^{\text {th }}$ century, indigenous or traditional native medicine is the type of medicine practiced by the Orang Asli of the Malay Peninsular and Pribumi of Sabah and Sarawak [9]. During this period, traditional Malay medicine was strongly influenced by the animistic culture of Hindu-Buddhism, which originated from India. Subsequently, with the introduction of Islam and with the arrival of the Chinese, the practice of medicine began to change, incorporating these new set of values [10]. At the $18^{\text {th }}$ century, Traditional Chinese Medicine practices began to take root in the Malayan soil. At the end of the $19^{\text {th }}$ century, modern medicine was brought in by the British and was taken up quickly due to its ease of practice and effectiveness.

During this period, T\&CM also started to appear in Malaysia. With the booming number of immigrants from China, the first voluntary T\&CM clinic was opened in Selangor state (Pei Shan Tang) and Kuala Lumpur (now known, Tung-Tshin Hospital) [11]. Then, in 1955, Federation of Chinese Physicians and Medicine Dealers Associations of Malaysia established Malaysia Chinese Medicine College for the first time [12]. By the $20^{\text {th }}$ century, modern medicine was the mainstream medicine practiced in Malaysia with T\&CM treatments available as a complement. Currently, T\&CM healthcare is increasingly gaining acceptance among Malaysians not merely in maintaining a healthy body, but also in treating ailments. T\&CM is becoming the most typical alternative remedy to standard medicine for Chinese, Malay and Indian in Malaysia communities [13].

In Malaysia, the integration of T\&CM and Western medicine is still in its infancy. In 2007, the first integrated Hospital was established in Kepala Batas, Pulau Pinang (Acupuncture, Malay Message, and Herbal Therapy as an Adjunct Treatment for Cancer Patients); in 2008, T\&CM services are introduced in Putrajaya Hospital, Putrajaya (Aupuncture, Malay Message, Herbal Therapy as an Adjunct Treatment for Cancer Patients and Malay Postnatal Treatment) and Sultan Ismail Hospital, Johor (Acupuncture, Malay Massage, Herbal Therapy as an Adjunct Treatment for Cancer Patients); in 2009, T\&CM units were also set up at Sultanah Nur Zahirah Hospital, Kuala Terengganu (Acupuncture, Malay Message), Duchess of Kent Hospital in Sandakan (Acupuncture, Malay Message), Sabah, and Sarawak general Hospital (Acupuncture, Malay Message). In 2010, T\&CM units were set up in Port Dickson Hospital, Negeri Sembilan (Acupuncture, Malay Message) and Sultanah Bahiyah Hospital in Alor Setar, Kedah (Acupuncture, Malay Message). Finally, in 2011, T\&CM unit was set up in Sultanah Hajah Kalsom Hospital, Cameron Highlands, Pahang (Malay Message, Acupuncture analgesia in Department of General Surgery).

In 2001 T\&CM Division, Ministry of Health, Malaysia developed the National T\&CM policy, and in 2007, developed and published practice guidelines and Good Practice Guidelines in each T\&CM clinical practice, such as practice Guideline on Islam Medicine/ Chiropractic/Herbal therapy as an Adjunct treatment for Cancer/ Malay Postnatal Care/Acupuncture/Cupping. In 2016, Malaysian government made another move to put Traditional and Complementary Medicine Act 2016 [Act 775] on gazette on 22 July 2016. T\&CM Division, Ministry of Health, Malaysia, defined therapeutic concept as healing in the form of medicine or therapy that has the capability to help in treating a disease or disability. It is used for 
Citation: Kim YJ (2017) The Current Studies of Education for a Traditional and Complementary Medicine in Malaysia. Altern Integr Med 6: 241. doi:10.4172/2327-5162.1000241

Page 3 of 6

either physical or mental health, which may be a medication, substance or an activity that supports the healing of one's mental or emotional health. On the other hand, wellness concept refers to modalities that assist in balancing positive health in an individual as exemplified by quality of life and a sense of well-being, as outlined in Table 1 [14].

\begin{tabular}{|c|c|c|}
\hline \multirow[t]{2}{*}{ Type of practice } & \multicolumn{2}{|l|}{ Treatment concept } \\
\hline & Therapeutic & Wellness \\
\hline Traditional Chinese Medicine & $\begin{array}{l}\text { Herbal Medicine } \\
\text { Acupuncture } \\
\text { Moxibustion } \\
\text { Tuina } \\
\text { Cupping }\end{array}$ & Qigong \\
\hline Traditional Malay Medicine & $\begin{array}{l}\text { Herbal Medicine } \\
\text { Urut Melayu (Malay Massage) } \\
\text { Indigenous Massage } \\
\text { Bekam (Cupping) }\end{array}$ & $\begin{array}{l}\text { Urut melayu (Malay Massage) } \\
\text { Indigenous Massage }\end{array}$ \\
\hline Islamic Medical Practice & Islamic Medical Practice (Ruqyah) & \\
\hline Traditional Indian Medicine & $\begin{array}{l}\text { Ayurveda } \\
\text { Siddha } \\
\text { Unani }\end{array}$ & Yoga \\
\hline Homeopathy & Homeopathy & \\
\hline Complementary Medicine & $\begin{array}{l}\text { Chripractor } \\
\text { Naturopathy } \\
\text { Osteopathy } \\
\text { Nutritional therapy } \\
\text { Hypnotherapy } \\
\text { Psychotherapy } \\
\text { Therapeutic Massage }\end{array}$ & $\begin{array}{l}\text { Spa Therapy } \\
\text { Reflexology } \\
\text { Aromatherapy } \\
\text { Thai Massage } \\
\text { Swedish Massage } \\
\text { Baliness/Javanese Massage } \\
\text { Shiatsu Massage } \\
\text { Color Vibration Therapy } \\
\text { Crystal Healing } \\
\text { Reiki } \\
\text { Aura metaphysic } \\
\text { Raoha } \\
\text { Ozone Therapy } \\
\text { Chelation therapy }\end{array}$ \\
\hline
\end{tabular}

Table 1: Modalities in T\&CM Practices.

\section{Brief introduction for education of T\&CM in Malaysia}

In Malaysia, the education pathway is comprised of four higher educational sectors, as outlined by the Malaysian Qualifications Framework. They are the skills, vocational, technical and academic sector. Each sector is supported by lifelong education pathways and is differentiated by learning outcomes, credit hour and student's learning time. In total, there are eight levels of qualifications, Levels 1 to 3 are Skills Certificates awarded by the Skills Sector, where Academic, Vocational and Technical Certificates are at Level 3. Meanwhile, Diploma and Advanced Diploma are at Level 4 and 5. Bachelor Degree is at Level 6. Master's Degree at Level 7 and for the Doctorates is at Level 8 [15].

For the institutions, the interview findings are showed in Table 2. Fourteen standards and criteria for diploma and bachelor degree have been developed to support the provision of education programs by both the public and private centers of higher education. To date, there are seven bachelor degree programs and six programs for diploma offered by these higher education institutions, as outlined in Table 3. In addition, the Malaysian Public Service Department has recognized three universities from China to offer the bachelor degree programs in Malaysia (Table 4) [16]. Currently, the local institutions listed in Table 5 are offering the courses, of which some are collaborated with the above-mentioned Chinese Universities.

T\&CM education in Malaysia has undergone 50 years of following China's Traditional Chinese Medicine education curriculums. Currently, Division of T\&CM, Ministry of Health and Ministry of Higher Education; has approved 11 institutions to offer T\&CM education. Students may major in Chinese Herbal Medicine (Traditional Chinese Medicine), Acupuncture or other T\&CM clinical 
Citation: Kim YJ (2017) The Current Studies of Education for a Traditional and Complementary Medicine in Malaysia. Altern Integr Med 6: 241.

Page 4 of 6

subjects, such as Tui-na, Natural Medicine, Homeopathy, Malay Medicine, Malay Massage, Ayurveda Medicine, Chiropractic, Reflexology, Aromatherapy and Islamic Medicine. Generally, clinical practice training programs in China, Taiwan or Australia include substantial proportion of clinical practice training. Each institution has created a capability-driven curriculum, embedding generic skills and professional training. Generally, Bachelor Degree courses have study duration of 15 semesters ( 3 semesters per year). In a year, here are 2 semesters of 16 weeks' study duration (14 teaching weeks, 1 study week and 1 examination week), and 1 semester of 9 weeks' study duration (7 teaching weeks, 1 study week and 1 examination week). The program consists of academic credits ranging from a minimum of 132 credits to maximum of 203 credits, including Traditional Chinese Medicine subjects, western medical science, basic science, professional studies, clinical training, and general studies. Regarding clinical practice training education, each institution has 10 months' duration (6 months in outpatients department in a TCM clinic, and 4 months in wards), To enhance students' clinical practice training, students attend 4 to 10 months of advanced clinical practice training at a local related hospitals or collaborated institutions in China, Taiwan or Australia. During this clinical practice training programs period, students collects medical history, clinical practice reports and final case presentations or graduate examination. Malay Medicine, Malay Massage, Ayurveda Medicine and Islamic Medicine Universities/ Colleges, on the other hand, conduct students' clinical practice training programs in India or other collaborated Universities/Colleges or Institutions in foreign countries.

\begin{tabular}{|c|c|c|}
\hline Variables & Frequency & $\begin{array}{l}\text { Valid } \\
\text { Percentage }\end{array}$ \\
\hline \multicolumn{3}{|l|}{ Interviewer's job level } \\
\hline Dean & 7 & 63.64 \\
\hline Head of Department & 4 & 36.36 \\
\hline Others & 0 & 0 \\
\hline \multicolumn{3}{|l|}{ Academic institute } \\
\hline University & 4 & 36.36 \\
\hline University College & 2 & 18.18 \\
\hline College & 5 & 45.46 \\
\hline \multicolumn{3}{|l|}{ Student numbers } \\
\hline$<50$ & 1 & 9.09 \\
\hline $51 \sim 70$ & 2 & 18.18 \\
\hline 71 90 & 1 & 9.09 \\
\hline $91 \sim 110$ & 6 & 54.55 \\
\hline$>111$ & 1 & 9.09 \\
\hline \multicolumn{3}{|l|}{ Courses offers $(\mathrm{N}=14)$} \\
\hline Traditional Chinese Medicine & 10 & 71.44 \\
\hline Homeopathy & 1 & 7.14 \\
\hline Chiropractic & 1 & 7.14 \\
\hline Urut melayu & 1 & 7.14 \\
\hline
\end{tabular}

\begin{tabular}{|c|c|c|}
\hline Islamic Medicine & 0 & 0 \\
\hline Ayurveda & 0 & 0 \\
\hline Others & 1 & 7.14 \\
\hline \multicolumn{3}{|l|}{ Course levels $(\mathrm{N}=14)$} \\
\hline Diploma/Foundation & 5 & 35.71 \\
\hline Academic degree & 9 & 64.29 \\
\hline Certificate & 0 & 0 \\
\hline \multicolumn{3}{|c|}{ Total graduate credits $(\mathrm{N}=14)$} \\
\hline 132 & 5 & 35.71 \\
\hline 203 & 9 & 64.29 \\
\hline Others & 0 & 0 \\
\hline \multicolumn{3}{|c|}{ Total clinical practice $(\mathrm{N}=14)$} \\
\hline 6 Months & 5 & 35.71 \\
\hline 10 Months & 8 & 57.14 \\
\hline 12 Months & 1 & 7.15 \\
\hline \multicolumn{3}{|c|}{ Affiliated International University/College } \\
\hline Yes & 9 & 81.82 \\
\hline No & 2 & 18.18 \\
\hline \multicolumn{3}{|c|}{ Affiliated Research Centre } \\
\hline Yes & 3 & 27.28 \\
\hline No & 8 & 72.72 \\
\hline \multicolumn{3}{|c|}{ Affiliated T\&CM hospitals } \\
\hline Yes & 3 & 27.28 \\
\hline No & 8 & 72.72 \\
\hline
\end{tabular}

Table 2: Social and Interviews Census.

\begin{tabular}{|l|l|}
\hline Bachelor Educational Programs & Diploma Training Programs \\
\hline $\begin{array}{l}\text { Bachelor of Traditional Chinese } \\
\text { Medicine (Acupuncture) }\end{array}$ & Diploma in Malay Massage \\
\hline $\begin{array}{l}\text { Bachelor of Traditional Chinese } \\
\text { Medicine }\end{array}$ & $\begin{array}{l}\text { Diploma in Traditional Chinese } \\
\text { Medicine (Acupuncture) }\end{array}$ \\
\hline $\begin{array}{l}\text { Bachelor of Complementary Medicine } \\
\text { (Natural Medicine) }\end{array}$ & Diploma in Natural Medicine \\
\hline Bachelor of Homeopathy & Diploma in Aromatherapy \\
\hline Bachelor of Malay Medicine & Diploma in Islamic Medicine \\
\hline Bachelor of Ayurveda Medicine & Diploma in Reflexology \\
\hline Bachelor of Chiropractic & \\
\hline
\end{tabular}

Table 3: Bachelors and diploma educational programs developed by Malaysian Qualifications Agency (MQA). 
Page 5 of 6

\begin{tabular}{|l|l|l|}
\hline No & Institutions & Course Offered \\
\hline 1 & Beijing University of Chinese Medicine & Bachelor of Chinese Medicine \\
\hline 2 & Nanjing University of Chinese Medicine & $\begin{array}{l}\text { Bachelor of Chinese Medicine } \\
\text { (Clinical Medicine) }\end{array}$ \\
\hline 3 & $\begin{array}{l}\text { Shanghai University of Traditional } \\
\text { Chinese Medicine }\end{array}$ & $\begin{array}{l}\text { Bachelor of Medicine } \\
\text { (Traditional } \\
\text { Medicine)ma }\end{array}$ \\
\hline
\end{tabular}

Table 4: T\&CM bachelor degree courses and universities from China, which are recognized by the Malaysian Public Sector.

\begin{tabular}{|c|c|c|}
\hline No & Institutions & Course Offered \\
\hline 1 & Southern University College, Skudai, Johor & $\begin{array}{l}\text { University Foundation } \\
\text { For Degree Program } \\
\text { (Traditional Chinese } \\
\text { Medicine) } \\
\text { Bachelor Degree of } \\
\text { Traditional Chinese } \\
\text { Medicine (Hons) }\end{array}$ \\
\hline 2 & $\begin{array}{l}\text { Tunku Abdul Rahman University (Sungai Long } \\
\text { Campus) }\end{array}$ & $\begin{array}{l}\text { Bachelor Degree of } \\
\text { Traditional Chinese } \\
\text { Medicine (Hons) }\end{array}$ \\
\hline 3 & INTI International University College & $\begin{array}{l}\text { Bachelor Degree of } \\
\text { Traditional Chinese } \\
\text { Medicine (Hons) }\end{array}$ \\
\hline 4 & International Medical University & $\begin{array}{l}\text { Bachelor of Science } \\
\text { (Hons) Chinese Medicine } \\
\text { Bachelor of Science } \\
\text { (Hons) Chiropractic }\end{array}$ \\
\hline 5 & Management and Science University & $\begin{array}{l}\text { Bachelor Degree of } \\
\text { Traditional Chinese } \\
\text { Medicine (Hons) } \\
\text { Diploma in Traditional } \\
\text { Chinese Medicine }\end{array}$ \\
\hline 6 & Xiamen University Malaysia Campus & $\begin{array}{l}\text { Bachelor Degree of } \\
\text { Traditional Chinese } \\
\text { Medicine (Hons) }\end{array}$ \\
\hline 7 & $\begin{array}{l}\text { International Institute of Management and } \\
\text { Technology }\end{array}$ & $\begin{array}{l}\text { Bachelor Degree of } \\
\text { Traditional Chinese } \\
\text { Medicine (Hons) }\end{array}$ \\
\hline 8 & Lincoln University College & $\begin{array}{l}\text { Diploma in Traditional } \\
\text { Chinese Medicine }\end{array}$ \\
\hline 9 & $\begin{array}{l}\text { Cyberjaya University College of Medical } \\
\text { Science }\end{array}$ & $\begin{array}{l}\text { Bachelor of Homeopathy } \\
\text { (Hons) }\end{array}$ \\
\hline 10 & Malacca College of Complementary Medicine & $\begin{array}{l}\text { Diploma in Natural } \\
\text { Medicine }\end{array}$ \\
\hline 11 & $\begin{array}{l}\text { Sultan Salahuddin Abdul Aziz Shah } \\
\text { Polytechnic }\end{array}$ & Diploma in Urut Melayu \\
\hline
\end{tabular}

Table 5: Institutions providing T\&CM courses in Malaysia.

\section{Conclusion}

According to the WHO's reports, Traditional Medicine continues to be widely used in many Asian countries, even though allopathic medicine is often readily available. In Malaysia, traditional forms of Malay, Chinese and Indian medicine are used extensively. Likewise, Latin America, $71 \%$ of the population in Chile, and $40 \%$ of the population in Colombia has used Traditional Medicine [17].

We had surveyed and interviewed the current status of education for traditional medicine in Malaysia. Beside 11 T\&CM Universities/ Colleges that exhibited the information for education of T\&CM in their website, we also received the detailed information via interview and from Division of T\&CM, Ministry of Health, or other institutions. However, we were not able to survey on the status of other Traditional \& Complementary Medicines.

From our studies, in most of bachelor/diploma courses developed by Malaysia Qualification Agency, and Division of T\&CM, each institution's examination has equal graduate academic credits. However, Universiti Tunku Abdul Rahman separated acupuncture subjects from other institutions, and Southern University College specially developed a clinical subject in its Traditional Chinese Medicine courses, which is herbal plants processing. INTI International University \& Colleges, on the other hand, collaborated with institutions in China, Taiwan and Australia for clinical practice training. This indicates that the practical education of traditional medicine in Malaysia has been considered after graduation. International Medical University collaborated its research with Beijing, Shanghai, Shandong and Guangzhou Universities of Traditional Chinese Medicine and RMIT in Australia, and built an Evidence-Based Centre of Excellence in Complementary Alternative Medicine. This shows regional leadership and exemplary practice in health/medicine education in T\&CM fields [18].

This study has a limitation of restricted data because Division of T\&CM has limited information and and the number of Universities/ Colleges with full information was small. Nevertheless, this study helped us understand the current status of education for Traditional \& Complementary medicine in Malaysia. These results would be the first stage information for an establishment of a strategy regarding the enhancement of Malaysia education for Traditional \& Complementary medicine.

\section{Acknowledgments}

The authors would like to thank all interviewed Deans and Head of Department of T\&CM Universities/Colleges, and Officers in Division of T\&CM, Ministry of Health, Malaysia, for supporting this study.

\section{References}

1. Wilkinson JM, Jelinek H (2009) Complementary medicine use among attendees at a rural health-screening clinic. Complement Ther Clin Pract 15: $80-84$

2. WHO (2013) Traditional medicine. Fact sheets.

3. Myeong YS, Ahn SY, Son Ch G (2016) Education for a Traditional Medicine in Medical Schools in Japan. Korean J Acupunct 33: 12-17.

4. OOi GL (1993) Chinese Medicine in Malaysia and Singapore: The business of healing. Am J Chin Med 21: 197-212.

5. Chotchoungchatchi S, Saralamp P, Jenjittikul T, Pornsiripongse S (2012) Medicinal plants used with Thai Traditional Medicine in modern healthcare services: A case study in Kabchoeng Hospital, Surin Province, Thailand J Ethnopharmacol 141: 193-205.

6. Siti ZM, Tahir A, Farah AI, Fazlin SM, Sondi S, et al. (2009) Use of traditional and complementary medicine in Malaysia: A baseline study. Complement Ther Med 17: 292-299. 
Citation: Kim YJ (2017) The Current Studies of Education for a Traditional and Complementary Medicine in Malaysia. Altern Integr Med 6: 241. doi:10.4172/2327-5162.1000241

Page 6 of 6

7. Elder WG, Hustedde C, Rakel D, Joyce J (2008) CAM curriculum activities to enhance professionalism training in medical schools. Complement Health Pract Rev 13: 127-133.

8. Division of T\&CM, Annual report 2011.

9. Chi YL (2012) Malaysia Traditional Chinese Medicine. J Shandong Chinese Med 21: 627-628.

10. Zeng Zh F. Malaysian Chinese Culture and Traditional Chinese Medicine. J Fujian College of TCM 17: 56-59.

11. Bao Y, Hu CP (2012) Current status for Traditional Chinese Medicine Education in Malaysia. World Journal of Integrated Traditional and Western Medicine. 7: 1082-1083.

12. Gao R, Zhang J (2011) Current status for Traditional Chinese Medicine in Malaysia. China Foreign Medical Treatment 25: 192.
13. Free Malaysia Today. Alternative medicines and the new age.

14. Division of T\&CM. National Policy of Traditional and Complementary Medicine.

15. Malaysia Qualifications Agency. Malaysian Qualifications Framework.

16. Public Sector Department of Malaysia.

17. WHO (2002) WHO Traditional Medicine Strategy 2002-2005. World Health Organization, Geneva.

18. Zhou WX (2012) Developing a Chinese Medicine programme in a western medical university. IeJSME 6: S155-158. 